\title{
Labor Support: An Aplication is Starting Again Come into Prominence
}

\section{Doğum Desteği: Yeniden Önem Kazanmaya Başlayan Bir Uygulama}

Samiye METE, Özlem ÇĊCEK

Dokuz Eylül Üniversitesi Hemşirelik Fakültesi, Doğum ve Kadın Hastalıkları Hemşireliği Anabilim Dalı, İzmir, Türkiye

\section{öz}

Doğum desteği, maternal, fetal ve neonatal açından oldukça yararlı bir bakımdır. Yabancı literatürde uzun yıllardır üzerinde çalışılan ve doğum sonuçlarına etkisi incelenen bu girişim, ülkemiz için oldukça yenidir. Ülkemizde doğum desteğinin önemini inceleyen araştırma sayısı oldukça sınırlıdır. Oysaki anne-çocuk sağlığı doğumhanede başlamaktadır. Doğumhanede çalışan hemşire ve ebelerin doğum desteğinin amaçlarını, faydalarını, tiplerini ve etkilerini bilmesi son derece önemlidir. Doğum desteği çeşitleri ve içerikleri ise intrapartum bakım veren sağlık profesyonelinin bakımını planlayabilmesi için önemlidir. Bu derlemede doğum desteği tüm yönleri ile el alınmakta ve ülkemizde süresine göre doğum desteği ilk olarak bu çalışmada sunulmaktadır.

Anahtar Kelimeler: Doğum desteği, destekleyici bakım, doğumhane hemşireliği

\section{ABSTRACT}

Labor support is more important care for maternal, fetal and neonatal. This implemenatation is new for our country but foreign literature is examined it's impact of birth outcomes. The number of research which investigating the importance of labor support is very limited in our country. However, mother-child health begins in the delivery room. Labor support's objectives, benefits, types and its effect are known by nurses and midwives are worked in the delivery room is extremely important. Also labor support's types and content is important to health professionals to plan the intrapartum care. Labor support is taken in hand all aspects in this review and according to time to the labor support is first presented in this studies in our country.

Keywords: Labor support, supportive care, delivery nurse

\section{Giriş}

Doğum desteği ya da doğumda destekleyici bakım, doğum eylemindeki bakımın önemli bir bölümünü oluşturmakta ve hemşirelerin önemli bir görevi olarak kabul edilmektedir (1). Güvenilir, maliyeti düşük ve kadınlar için oldukça değerli bir bakım olan "doğum desteği” nin, kadınlar tarafından ilaç uygulamaları ve tıbbi destekten çok daha önemli bir girişim olduğu ifade edilmektedir $(2,3)$.

"Doğum desteği/doğumda destekleyici bakım” kavramı farklı şekillerde tanımlanmıştır:

- Barret ve Stark'a göre (2), normal doğum sürecinin ilerlemesini desteklemek,

- Davis ve Hodnett (3) ve Hodnett, Gates, Hofmeyr ve Skala’ya göre (4), doğum eylemi süresince kadına bakım vermek ve sosyal destek sağlamak,

- Sleutel (5) ve Rubin’e göre (6) "kadının doğum yapma gücünü kendi kontrolünde kullanmasını sağlamak”,

- Kadın Sağlı̆̆ı, Obstetrik ve Yenidoğan Hemşireler Birliği’ne göre (7), profesyoneller tarafından verilen ve doğum sonuçlarını geliştiren bakım,

- Sauls’a göre (8), doğumhane hemşiresinin, gebenin doğum süreciyle baş etmesini sağlayacak tutum ve davranışları,

- Adams ve Bianchi'e göre (9), doğumhane hemşiresileri ve araştırmacılar tarafından uygulanan non-farmakolojik ağrı yönetimi ve kadının, doğum süresince desteklenmesidir.

Doğum desteğinin amaçları; doğum yapan kadına aktif olarak yardım etmek, duygusal ihtiyaçlarını ve isteklerini karşılamak, rahatlığını sağlamak, doğum sonuçlarını geliştirmek, benlik saygısını arttırmak, olumlu doğum deneyimi yaşamasını sağlamak ve annelik rolüne geçişi kolaylaşırımaktır (10-13). Aynı zamanda doğum hemşireleri tarafında uygulanan doğum desteği ile kadınların vaginal doğum yapmalarında da etkili olabilecekleri bilinmektedir (14). Hemşirelik bakım uygulamalarında doğum

Cite this article as: Mete S, Çiçek Ö. Labor Support: An Aplication is Starting Again Come into Prominence. Bezmialem Science 2018; 6: 138-42. 
desteğinin önemine vurgu yapılsa da hemşirelerin \%12,4̌ünün doğum desteğine zaman ayırdıkları belirlenmiştir (15). Hemşirelerin doğum desteği uygulamasına engel olan durumlar ise; personel eksikliği, teknoloji kullanımının artması, kurumsal düzenlemelerin uygun olmayışı ve hemşirelik dışı işlerin hemşireler tarafından yapılması olarak ifade edilmiştir $(3,5,16,17)$.

Literatür incelendiğinde doğum desteğinin farklı sürelerle uygulandığı ancak sadece bir araştırmada uygulanan doğum desteğinin süresinin belirtildiği görülmektedir (18). Farklı araştırmacılar tarafından farklı içerikler (Tablo 1, fiziksel, duygusal vb.) ile uygulanan doğum desteği için hangi içeriğin ne kadar uygulanması ile ilgili ise herhangi bir çalışmaya ulaşılamamıştır. Bu nedenle doğum desteğinin ve hangi içeriğin ne kadar uygulanabileceğini ortaya koyacak çalısmalara gereksinim vardır. Hemşirelerin doğum desteği uygulamama gerekçelerini inceleyen çalş̧malar incelendiğinde ise bir çok engelleyici faktör olduğu görülmektedir. Sonuç olarak, engelleyici faktörlere bağlı olarak doğum desteği uygulanma durumu ile ilgili farklı sonuçlarla karşılaşılmaktadır.

\section{Doğum Desteğinin Maternal, Fetal ve Neonatal Yararları} (Yararlar Şekil 1 ve 2'de yer almaktadır)

Doğum desteği uygulaması sadece maternal değil, aynı zamanda fetal ve neonatal yönden de yararlıdır. Yapılan çalışmalarla doğum desteğinin yararları Şekil 1'de yer almaktadır. Bazı çalışmalarda ise doğum desteği verilen kadınlar ile rutin bakım alan kadınların doğum sonuçları arasında fark olmadığı gösterilmiştir (Şekil 2).

Doğum desteğinin maternal, fetal ve neonatal etkilerini inceleyen çalışmalar incelendiğinde farklı sonuçlara ulaşıldığı gö-

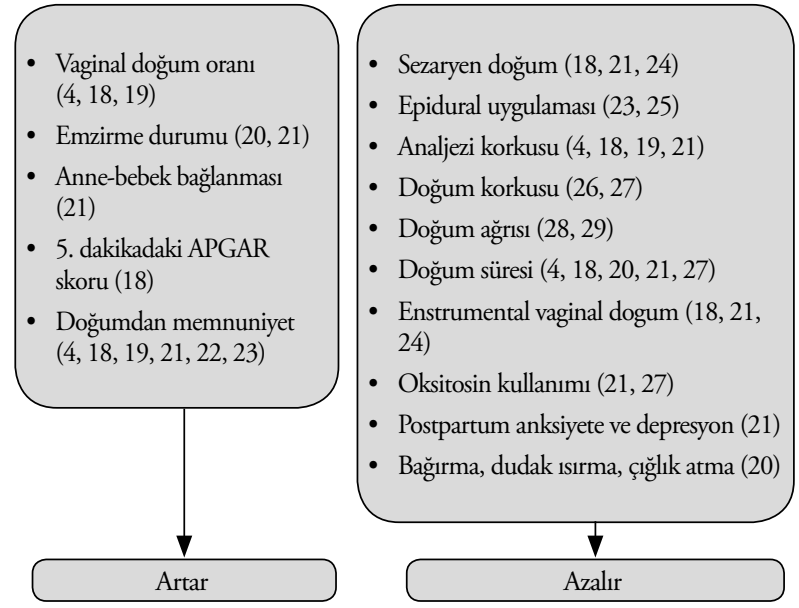

\section{Şekil 1. Doğum desteğinin yararı}

- Sezaryan doğum oranlan $(23,30)$

- Enstrumental doğum $(23,30)$ Epidural uygulaması $(27,30)$

- Doğum süreleri (27)

- Oksitosin kullanımı, $(23,27)$

- Perinea! travma (27)

- Emzirme durumu $(18,23)$

- Postpartum depresyon (23) Yenidoğanın yoğun bakım ihtiyacı (23)

Fark yok

Şekil 2. Doğum desteği ve rutin bakım uygulamasının birbirine üstünlüğünün olmadığı doğum sonuçları

Tablo 1. Doğum desteğinin içeriğine göre sınıflandırılması

\begin{tabular}{|c|c|c|c|c|c|c|c|}
\hline \multirow[b]{2}{*}{ Araştırmacı } & \multicolumn{3}{|c|}{ Doğum Desteğinin İçeriği } & \multirow[b]{2}{*}{ Cesaretlendirme } & \multirow[b]{2}{*}{ Savunuculuk } & \multirow[b]{2}{*}{$\begin{array}{c}\text { Eş } \\
\text { desteği }\end{array}$} & \multirow[b]{2}{*}{$\begin{array}{c}\text { Somut / } \\
\text { Teknik destek }\end{array}$} \\
\hline & $\begin{array}{l}\text { Fiziksel } \\
\text { rahatlık }\end{array}$ & $\begin{array}{c}\text { Duygusal } \\
\text { destek }\end{array}$ & $\begin{array}{c}\text { Bilgilendirme / } \\
\text { Eğitim verme }\end{array}$ & & & & \\
\hline Hodnett (1) & $x$ & $x$ & $x$ & & $x$ & $x$ & \\
\hline Davies ve Hodnett (3) & $x$ & $x$ & $x$ & & & & \\
\hline Hodnett ve ark. (4) & $x$ & $x$ & $x$ & & $x$ & & \\
\hline Sauls (8) & $x$ & $x$ & $x$ & & $x$ & & $x$ \\
\hline Miltner (11) & $x$ & $x$ & $x$ & $x$ & & & \\
\hline $\begin{array}{l}\text { Gale-Fothergill, Bourbonnais } \\
\text { ve Chamberlain (15) }\end{array}$ & $x$ & $x$ & $x$ & & $x$ & & \\
\hline $\begin{array}{l}\text { Payant, Davies, Graham, } \\
\text { Peterson ve Clinch (25) }\end{array}$ & $x$ & $x$ & $x$ & & $x$ & & \\
\hline Gagnon ve Waghorn (30) & $x$ & $x$ & $x$ & & $x$ & & \\
\hline McNiven, Hodnett ve & & & & & & & \\
\hline O’Brein Pallas (32) & $x$ & $x$ & $x$ & & $x$ & & \\
\hline Bianchi ve Adams (33) & $x$ & $x$ & $x$ & & $x$ & & \\
\hline Hodnett, Gates, Hofmeyr ve & & & & & & & \\
\hline Sakala (34) & $x$ & $x$ & $x$ & & $x$ & & \\
\hline Taylor (35) & $x$ & $x$ & $x$ & & & & $x$ \\
\hline NICE (36) & $x$ & $x$ & $x$ & & $x$ & & \\
\hline
\end{tabular}


rülmektedir. Destekleyici bakımın vaginal doğum oranlarıını arttırdığı ise bir çok çalışma ile desteklenmiştir. Doğum desteğinin doğum sonuçları üzerine olumsuz herhangi bir etkisinin olmaması, bu desteğin gebelere sağlanması için hemşire ve ebelerin de desteklenmeleri gerektiğini düşündürmektedir. Çünkü çalışma sonuçlarının tamamı kadınların destekleyici bakımdan memnun olduklarını göstermektedir. Bu nedenle doğumda destekleyici bakımın geliştirilmesine yönelik çalışmaların arttırılmasına ve sonuçlarının araştırmalar ile ortaya konmasına gereksinim vardır.

\section{Doğum Desteğinin Çeşitleri}

Literatürde doğum desteği farklı şekillerde sınıflandırılmıştır. $\mathrm{Bu}$ sınıflandırmalar doğum desteğinin içeriğine, desteğin uygulanış süresine ve desteği veren kişilere göre değiş̧mektedir.

\section{Doğum Desteğinin İ̧eriğine Göre Sinıflandırılması}

Doğum desteği içeriğine göre; fiziksel rahatlık, duygusal destek, bilgilendirme/eğitim verme, cesaretlendirme, savunuculuk, eş desteği ve somut/teknik destekten oluşmaktadır (Tablo 1). Tablo 1'deki içeriklerin dışında Hottenstein (37) doğum desteği içeriğini Watson'ın İnsan Bakım Teorisi'ne göre işitsel, görsel, koku alma, dokunsal, kinestetik ve bilinçli bakım olarak ifade etmektedir. Bu bilgilerden yola çıkılarak güncel uygulamalar doğrultusunda doğumhane hemşirelerinin bakım içeriklerini geliştirmeleri gerektiği vurgulanmaktadır (37). Literatür incelendiğinde bazı doğum desteği çeşitlerinin farklı kategoriler altında toplandığı da görülmektedir. Örneğin Bryanton, Fraser ve Sullivan (38), övgü ve cesaretlendirmeyi hem bilgisel hem de duygusal desteğin içinde ele almaktadır. Doğumhanede çalışan hemşirelerin bakım verdikleri kadınlara uygun doğum desteğini seçmeleri önerilmektedir (9).

Yapılan araştırmalar duygusal desteğin, fiziksel destekten daha önemli olduğunu göstermektedir $(38,39)$. Özellikle duygusal destek ve fiziksel desteğin doğum komplikasyonlarını önemli ölçüde azalttığı gösterildiği için doğum ve doğum sonuçlarına etkisini belirlemek için daha fazla çalışma yapmak önem kazanmaktadır (18).

Doğum desteğinin içeriğine bakıldığında oldukça geniş ve çeşitli sınıflandırmaların olduğu görülmektedir. Bu nedenle doğum desteği verecek kişilerin çok donanımlı olması gerekmektedir. Doğum desteği verecek kişilerin bu yeterliliğe sahip olabilmesi için hizmet içi eğitimler ve sertifika programları ile desteklenmelerine gereksinim bulunmaktadır. Özellikle duygusal destek, savunuculuk, eğitim ve danışmanlık alanlarında destek sağlanabilmesi için hemşire ve ebelerin çok iyi desteklenmesine gereksinim duyulmaktadır. Hemşire ve ebelerin bu konularda eğitim alması kadar kişisel gelişim programlarına katılmaları da yarar sağlayabilir.

\section{Doğum Desteğinin Süreye Göre Sinıflandırılması}

Doğum desteği, süresine göre sınıflandırıldığında literatürde karşımıza iki tip doğum desteği çıkmaktadır: Sürekli doğum desteği ve aralıklı doğum desteği (18). Doğum desteğini süre- genellikle sürekli doğum desteğinden söz edildiği ise ayrı bir tartışma konusudur.

\section{a) Sürekli Doğum Desteği}

Literatürde "Sürekli doğum desteği" kavramı ile ilgili birçok tanım bulunmaktadır. Bu tanımlar şunlardır:

- Doğum desteği sağlayan kişinin doğumun \%80-90'ından daha uzun süre boyunca gebeyle birlikte olması, gebeyi cesaretlendirmesi ve rahatlatıcı dokunuşlarda bulunması (3),

- Yirmi dakika kahve molası ve iki defa 30 'ar dakikalık yemek molası hariç, hemşirenin doğumun başından sonuna kadar gebeyle birlikte olması (30),

- Gebenin tuvalet ihtiyacı dışında, doğum süresinin \%80'inden daha uzun sürede hemşire/ebeden bakım alması $(3,18,36)$,

- Gebenin tuvalet ihtiyacını gidermesi, yalnız kalmak istediği zaman yalnız bırakılması ve hemşire/ebenin çok kısa zaman dilimleri haricinde gebenin yanında olması (18) ve

- Doğum süresinin minimum \%80'ini kapsayacak şekilde doğum desteği uygulanmasıdır (40).

Uluslararası Lamaze Kuruluşu da normal doğum eyleminde sürekli destek sağlanmasının oldukça önemli olduğunu vurgulamaktadır (41). Ayrıca kanıt çalışmalarıyla da "sürekli doğum desteği” nin A düzeyinde kanıt kalitesi olan en iyi girişim olduğu vurgulanmaktadır (20). Sürekli doğum desteği verilen gebelerde doğum ağrısı, oksitosin kullanımı, forsepsle doğum oranı, sezaryen doğum oranı ve analjezi kullanımı azalırken, doğumdan memnuniyetin arttığı saptanmıştır $(3,4,18,19$, 22, 42, 43). Ayrıca sürekli doğum desteği alan kadınlarda doğum süresinin de kısaldığı belirlenmiştir $(18,43)$. Zhang ve arkadaşlarının çalışmasında, sürekli destek alan kadınların doğum süresinin 2.8 saat kısaldığı belirlenmiştir (42).

\section{b) Aralıklı Doğum Desteği}

“Aralıklı doğum desteği” kavramı ile ilgili literatürde tek tanıma ulaşılmıştır. Bu tanıma göre, gebenin tuvalet ihtiyacının olması ve yalnız kalmak istemesi haricinde de gebenin yalnız bırakılması" olarak tanımlanmaktadır (18). Bu tanımdan yola çıkılarak sürekli doğum desteğinin "doğumhaneye kabulden, doğum anına kadar geçen sürenin \%80 ve daha fazlası" olarak kabul edilir ise biz yazarlar olarak aralıklı doğum desteğini “verilen doğum desteği süresinin \%80'den daha az olması" olarak tanımlamaktayız.

Scott, Berkowitz ve Klaus'un (18) literatürde doğum desteğini karşılaştıran ilk meta-analize göre; aralıklı doğum desteği alan gebelerin doğum ağrısı, doğum süresi, doğum eylemi süresince analjezi kullanımı ve operatif doğum oranları sürekli doğum desteği alan kadınlardan daha yüksek bulunmuştur (18). Çiçek (44) tarafından yapılan "Doğum Eyleminde Uygulanan Hemşirelik Bakımının Doğum Korkusu, Ağrısı, Süresi ve Doğum Deneyiminden Memnuniyete Etkisi” isimli doktora 
tezinde, doğum eyleminde aralıklı doğum desteği uygulanan kadınların indüksiyon kullanımı, amniyotomi uygulanması ve epidural anestezi kullanımının rutin hemşirelik bakımı alan kadınlara göre daha az olduğu sonucuna ulaşılmıştır. Ancak literatürde aralıklı doğum desteğinin etkinliğini gösteren araştırma sayısının yetersiz olmasından dolayı aralıklı doğum desteğini değerlendirecek daha fazla çalışmaya gereksinim vardır.

OECD ülkelerinde 1000 kişiye ortalama 9,1 hemşirenin bakım vermesine karşılık, Ülkemizde giderek artan doğum oranları ve 1000 kişiye ortalama 2,0 hemşirenin denk geldiği göz önüne alındığında (45) sürekli doğum desteğinin ülkemiz koşullarında uygun olmadığı düşünülmektedir. Aralıklı doğum desteği verildiğinde olumlu sonuçlar elde edildiğini gösteren daha fazla çalışmaya ulaşılması durumunda ise aralıklı doğum desteğinin rutin uygulamaya konması önerilebilir. Böylece yetersiz olan hemşire ve ebelerin daha etkin bir şekilde sorumluluklarını yerine getirmesi ve gebelerin de doğum desteğinin olumlu yönlerinden yarar görmeleri sağlanmış olacaktır.

\section{Doğum Desteğinin Aynı ya da Değişen Kişiler Tarafından Uygulanmasına Göre Yapılan Sınıflama}

Doğum eyleminde destekleyici bakım aynı kişi ya da değişen kişiler tarafından sağlanabilir. Bu konuda yeterince veri bulunmamaktadır. Ancak uygulamalarda doğum yapacak olan kadının doğumunun başından sonuna kadar aynı kişinin bakım verdiği uygulamalar olduğu gibi, belirli çalışma saati sonunda değişen kişiler tarafından bakım verildiği de bilinmektedir. Bu iki uygulama sonrasında doğum sonuçlarının nasıl etkilendiğini gösteren çalışmaya ise ulaşılamamıştır.

\section{Sonuç}

Son yıllarda "doğumda destekleyici bakım" yeniden önem kazanmaya başlamıştır. Doğum desteği kavramının içeriği ve uygulanma süresi ile ilgili ortak bir görüş bulunmamaktadır. Doğum desteği temel olarak sürekli ve aralıklı olarak iki şekilde tanımlanmaktadır. Aralıklı doğum desteği ile ilgili tanımlamalarda da farklılıklar bulunmaktadır.

Doğum desteğinin etkisini inceleyen araştırmalar çoğunlukla sürekli doğum desteğinin etkisini incelemektedir. Sürekli doğum desteğinin maternal, fetal ve neonatal sağlık açısından olumlu etkileri olduğu görülmektedir. Ancak aralıklı doğum desteğinin tanımı, içeriği ve sonuçları hakkında yeterince araşıırmaya ulaşılmamaktadır. Aralıklı doğum desteği ile ilgili olan sınırlı sayıdaki araştırmaya göre maternal, fetal ve neonatal açıdan olumlu sonuçları olduğu saptanmıştır. Ayrıca doğum desteğinin sürekli aynı kişi yada farklı kişiler tarafından verilmesinin sonuçları hakkında da ise veriye ulaşılamamışıır.

Araştırma sonuçlarının da gösterdiği gibi, sürekli doğum desteğinin yararlarına ilişkin iyi düzeyde kanıtlar var iken aralıklı doğum desteğine ilişkin yeterli kanıt olmadığı anlaşılmaktadır. Bununla birlikte birebir sürekli doğum desteği vermenin yetersiz hemşire ve ebe sayılarından dolayı uygulanması zor bir girişim olduğu bilinmektedir. Bu nedenle olumlu doğum sonuçlarına ulaşabilmek için aralıklı doğum desteği verilme- sinin yararlı olacağı düşünülmektedir. Ancak aralıklı doğum desteğinin doğum sonuçlarına etkisini inceleyecek daha fazla çalışmaya gereksinim bulunmaktadır. Maternal, fetal ve neonatal açıdan oldukça fazla yararı olan doğum desteğinin uygulanabilmesi için; hemşire/gebe sayısının, kurumsal politikaların ve güncel bilimsel bilgi ile yaklaşımların göz önünde bulundurulması gerekmektedir.

Hakem Değerlendirmesi: Dış Bağımsız.

Yazar Katkıları: Fikir - S.M., Ö.Ç.; Tasarım - S.M., Ö.Ç.; Denetleme S.M., Ö.Ç.; Kaynaklar - Ö.Ç.; Veri Toplama ve/veya İşleme - Ö.Ç.; Analiz ve/veya Yorum - S.M., Ö.Ç.; Literatür Taraması - Ö.Ç.; Yazıyı Yazan - Ö.Ç.; Eleştirel İnceleme - S.M.

Çıkar Çatışması: Yazarlar çıkar çatışması bildirmemişlerdir.

Finansal Destek: Yazarlar bu çalışma için finansal destek almadıklarını beyan etmişlerdir.

Peer-review: Externally peer-reviewed.

Author Contributions: Concept - S.M., Ö.Ç.; Design - S.M., Ö.Ç.; Supervision - S.M., Ö.Ç.; Resources - Ö.Ç.; Data Collection and/or Processing Ö.Ç.; Analysis and/or Interpretation - S.M., Ö.Ç.; Literature Search - Ö.Ç.; Writing - Ö.Ç.; Critical Review - S.M.

Conflict of Interest: No conflict of interest was declared by the authors.

Financial Disclosure: The authors declared that this study has received no financial support.

\section{Kaynaklar}

1. Hodnett ED. Nursing support of the laboring woman. J Obstet Gynecol Neonatal Nurs 1996; 25: 257-64. [CrossRef]

2. Barrett SJ, Stark MA. Factors associated with labor support behaviors of nurses. J Perinat Educ 2010; 19: 12-8. [CrossRef]

3. Davies BL, Hodnett E. Labor support: Nurses' self-efficacy and views about factors influencing implementation. J Obstet Gynecol Neonatal Nurs 2002; 31: 48-56. [CrossRef]

4. Bohren MA, Hofmeyr GJ, Sakala C, Fukuzawa RK, Cuthbert A. Continuous support for women during childbirth. The Cochrane Library 2017; 7. [CrossRef]

5. Sleutel M, Schultz S, Wyble K. Nurses' views of factors that help and hinder their intrapartum care. J Obstet Gynecol Neonatal Nurs 2007; 36: 203-11. [CrossRef]

6. Rubin R. Maternity nursing stops too soon. Am J Nurs. 1975; 75 : 1680-84. [CrossRef]

7. Association of Women's Health, Obstetric and Neonatal Nurses. Clinical position statement: Continuous labor support for every women. J Obstet Gynecol Neonat Nurs 2018; 47: 73-4. [CrossRef]

8. Sauls DJ. Dimensions of professional labor support for intrapartum practice. J Nurs Scholarsh 2006; 38: 36-41. [CrossRef]

9. Adams ED, Bianchi AL. A practical approach to labor support. J Obstet Gynecol Neonatal Nurs 2008; 37: 106-15. [CrossRef]

10. Sleutel RM. Intrapartum nursing: Integrating Rubin's framework with social support theory. JOGNN 2003; 32: 76-82. [CrossRef]

11. Miltner RS. Identifying labor support actions of intrapartum nurses. JOGNN 2000; 29: 491-99. [CrossRef]

12. Yuenyong S, O'Brien B, Jirapeet V. Effects of labor support from close female relative on labor and maternal satisfaction in a Thai setting. JOGNN 2012; 41: 45-56. [CrossRef] 
13. Waldenström U, Hildingsson I, Rubertsson C, Radestad I. A negative birth experience: Prevalence and Risk Factors in a national sample, BIRTH 2004; 31: 17-26. [CrossRef]

14. Simpson KR, Lyndon A. Labor Nurses' Views of Their Influence on Cesarean Birth. MCN Am J Matern Child Nurs 2017; 42: 81-7. [CrossRef]

15. Gale J, Fothergill-Bourbonnais F, Chamberlain M. Measuring nursing support during childbirth. MCN Am J Matern Child Nurs 2001; 26: 264-71. [CrossRef]

16. Graham ID, Logan J, Davies B, Nimrod C. Changing the use of electronic fetal monitoring and labor support: A case study of barriers and facilitators. BIRTH 2004; 31: 293-301. [CrossRef]

17. Simpson KR, Lyndon A. Consequences of delayed, unfinished, or missed nursing care during labor and birth. J Perinat Neonat Nurs 2016; 31: 32-40. [CrossRef]

18. Scott KD, Berkowitz G, Klaus M. A comparison of intermittent and continuous support during labor: a meta-analysis. Am J Obstet Gynecol 1999a; 180: 1054-59. [CrossRef]

19. Hodnett ED, Gates S, Hofmeyr GJ, Sakala C. Continuous support for women during childbirth (Review) The Cochrane Library. 2013; 10. [CrossRef]

20. Berghella V, Baxter JK, Chauhan SP. Evidence-based labor and delivery management. Am J Obstet Gynecol 2008; 199: 445-54. [CrossRef]

21. Gençalp NS. Doğum eyleminde anneye verilen destekleyici hemşirelik bakımının doğum sürecine etkisi. 1. Uluslararası 8. Ulusal Hemşirelik Kongre Kitab1, Antalya, 2000; 276-79.

22. Scott KD, Klaus PH, Klaus MH. The obstetrical and postpartum benefits of continuous support during childbirth. J Womens Health 1999b; 8: 1257-64. [CrossRef]

23. Corbett AC, Callister LC. Nursing Support During Labor. Clin Nurs Res 2000; 9: 70-83. [CrossRef]

24. Gordon NP, Walton D, McAdam E, Derman J, Gallitero G, Garrett L. Effects of providing hospital-based doulas in health maintenance organization hospitals. Obstet Gynecol 1999; 93: 42242-6. [CrossRef]

25. Payant L, Davies B, Graham ID, Peterson WE, Clinch J. Nurses' intentions to provide continuous labor support to women. J Obstet Gynecol Neonatal Nurs 2008; 37: 405-14. [CrossRef]

26. Conniff J, Dresang L. Does continuous labor support decrease rates of cesarean and assisted vaginal delivery?. Evidence-Based Practice 2016; 19: 5.

27. Haines HM, Hildingsson I, Pallant JF, Rubertsson C. The role of women's attitudinal profiles in satisfaction with the quality of their antenatal and intrapartum care. J Obstet Gynecol Neonatal Nurs 2013; 42: 428-41. [CrossRef]

28. Isbir GG, Serçekuș P. The Effects of intrapartum supportive care on fear of delivery and labor outcomes: A single-blind randomized controlled trial. J Nurs Res 2017; 25: 112-19.

29. Wilson CL, Sirmpson JA. Childbirth pain, attachment orientations, and romantic partner support during labor and delivery. Personal Relationships 2016; 23: 622-44. [CrossRef]
30. Gagnon AJ, Waghorn K. Supportive care by maternity nurses: A work sampling study in an intrapartum unit. BIRTH 1996; 23: 1-6. [CrossRef]

31. Gagnon AJ, Waghorn K, Covell C. Randomized trial of one-to-one nurse support of women in labor BIRTH 1997; 24: 71-7. [CrossRef]

32. McNiven P, Hodnett ED, O'Brien-Pallas LL. Supporting women in labor: A work sampling study of the activities of labor and delivery nurses. BIRTH 1992; 19: 3-8. [CrossRef]

33. Bianchi AL, Adams ED. Doulas, labor support, and nurses. Int J Childbirth Educ 2004; 19: 24-30.

34. Hodnett E, Gates S, Hofmeyr G, Sakala C. Continuous support for women during childbirth. Cochrane Database of Systematic Reviews 2003. [CrossRef]

35. Taylor JS. Caregiver support for women during childbirth: Does the presence of a labor-support person affect maternal-child outcomes? Am Fam Physician 2002; 6: 1205-06

36. National Institute for Health and Care Excellence, Intrapartum care: Care of healthy women and their babies during childbirth. Available from: URL: https://www.nice.org.uk/guidance/cg55/resources/ guidance-intrapartum-care-care-of-healthy-women-and-their-babiesduring-childbirth-pdf

37. Hottenstein SE. Continuous labor support. Lifelines 2005; 9: 243-47. [CrossRef]

38. Bryanton J, Fraser-Davey H, Sullivan P. Women's perceptions of nursing support during labor. J Obstet Gynecol Neonatal Nurs 1994; 23: 638-44. [CrossRef]

39. Mackey MC, Flanders-Stepans ME. Women's evaluations of their labor and delivery nurses. J Obstet Gynecol Neonatal Nurs 1994; 23: 41320. [CrossRef]

40. Simkin P, Bolding A. Update on nonpharmacologic ap- proaches to relieve labor pain and prevent suffering. J Midwifery Womens Health 2004; 49: 489-556. [CrossRef]

41. Green J, Amis D, Hotelling BA. Care practice: continuous labor support. J Perinat Educ 2007; 16: 25-8. [CrossRef]

42. Zhang J, Bernasko JW, Leybovich E, Fahs M, Hatch, M. C. Continuous labor support from labor attendant for primiparous women: A metaanalysis. Obstetrics \& Gynecology 1999; 88: 739-44. [CrossRef]

43. Kashanian M, Javadi F, Haghighi MM. Effect of continuous support during labor on duration of labor and rate of cesarean delivery. Int J Gynaecol Obstet 2010; 109: 198-200. [CrossRef]

44. Çiçek Ö. Doğum Eyleminde Uygulanan Hemşirelik Bakımının Doğum Korkusu, Ağrısı, Süresi ve Memnuniyete Etkisi. Dokuz Eylül Üniversitesi Sağlık Bilimleri Enstitüsü Doktora Tezi, İzmir. 2016.

45. Health at a Glance 2017 OECD Indicators. Available from: https:// www.oecd-ilibrary.org/docserver/health_glance-2017-en.pdf?expires $=1$ 526838193\&id=id\&accname $=$ ocid $53022151 \&$ checksum $=17219328$ FB1EA557F2D7BD1D58E2B5A8 